\title{
An Extended Synthesis for Evolutionary Biology
}

\author{
Massimo Pigliucci \\ Departments of Ecology and Evolution and of Philosophy, Stony Brook University, \\ Stony Brook, New York, USA
}

\begin{abstract}
Evolutionary theory is undergoing an intense period of discussion and reevaluation. This, contrary to the misleading claims of creationists and other pseudoscientists, is no harbinger of a crisis but rather the opposite: the field is expanding dramatically in terms of both empirical discoveries and new ideas. In this essay I briefly trace the conceptual history of evolutionary theory from Darwinism to neo-Darwinism, and from the Modern Synthesis to what I refer to as the Extended Synthesis, a more inclusive conceptual framework containing among others evo-devo, an expanded theory of heredity, elements of complexity theory, ideas about evolvability, and a reevaluation of levels of selection. I argue that evolutionary biology has never seen a paradigm shift, in the philosophical sense of the term, except when it moved from natural theology to empirical science in the middle of the 19th century. The Extended Synthesis, accordingly, is an expansion of the Modern Synthesis of the 1930s and 1940s, and one that-like its predecessor-will probably take decades to complete.
\end{abstract}

Key words: evolutionary theory; Darwinism; Modern Synthesis; Extended Synthesis; philosophy of science; natural selection; agency; efficacy; scope

The scientific theory of evolution is just over 150 years old. In 2009 scientists all over the world are celebrating one and a half centuries since the publication of The Origin of Species (Darwin 1859), which followed closely the presentation of a joint paper by Darwin and Wallace (1858) at the Linnean Society of London. Rather suddenly, the concept of evolution moved firmly away from being a quasimystical notion, and biology left Paley's (1802) natural theology forever behind to enter the realm of respectable science, just like physics had done two centuries before.

Of course, what we consider "evolutionary theory" today is not Darwin's original work, not any more than today's physics is "Newtonian" in nature. Instead, we currently work under the conceptual framework that was built over the course of several decades at the beginning

Address for correspondence: Massimo Pigliucci, Departments of Ecology and Evolution and of Philosophy, Stony Brook University, Stony Brook, NY 11794.pigliucci@genotypebyenvironment.org of the 20th century and is well known as the Modern Synthesis (MS; Mayr \& Provine 1980). The goal of this essay is to summarize why early 21st century biology is poised to take the next step in evolutionary theory to produce what is being referred to as the Extended Synthesis (ES) (Pigliucci \& Muller 2010).

To appreciate this perspective of where the field is going, we need to understand where it came from and why it developed the way it did. These are tasks where historians and philosophers of science complement the practicing evolutionist, with the three disciplines combining efforts to identify a broader field of "theory" than is customary in everyday science. We shall see that both the original Darwinism and the MS went through at least two distinct incarnations and that each iteration of evolutionary theory addressed problems left unresolved by the previous one. This will then set the stage for the identification of issues not tackled by the MS itself, which will lead us to sketch an ES. At the end of my discussion I will argue that 
evolutionary biology has not undergone a paradigm shift since Darwin and Wallace's work; instead, its progress can be best understood in terms of Gould's 2002 model of a continuously expanding conceptual tree.

\section{A Brief Conceptual History of Evolutionary Theory}

The concept of evolution as change over time had, of course, been around before Darwin and Wallace's seminal report, for instance, in the writings of Darwin's grandfather, Erasmus. Darwin and Wallace, however, provided three fundamental advances: the clear presentation of two cardinal concepts for the new theory, as well as a wealth of evidence from a variety of fields to support the inference that the theory was in fact correct. The cardinal concepts were (1) common descent of all organisms from one (or a few) original ancestors and (2) natural selection as the process responsible for the apparent "fit" between organisms and their environment. The evidence came from many fields, with biogeography, comparative anatomy, behavioral ecology, and paleontology among them.

The new theory was immediately controversial, and not just for its perceived theological implications. Darwin devoted time and energy to convince major philosophers of his time, such as William Whewell, that his theory constituted good science. Whewell was engaged in a dispute with John Stuart Mill on the best way to improve on Francis Bacon's notion of induction, which was considered the centerpiece of the scientific method. Mill's position was closer to Bacon's, that new observations represented a starting point for generating novel hypotheses. Whewell, however, thought that hypotheses had to guide scientific discovery and the collection of new observations. In this context, Darwin's work in The Origin of Species was initially dismissed as an egregious example of deduction, and therefore bad science. This was obviously not the case: Darwin's method ac- tually followed closely what Whewell referred to as "consilience," a convergence of different sources of evidence toward the same inference. Indeed, Darwin himself wrote to a friend: "How odd it is that anyone should not see that all observation must be for or against some view if it is to be of any service!" (Darwin \& Seward 1903). Today it might seem odd that a scientist was at pains to justify his research to a pair of philosophers, and yet evolutionary biology still partially retains the unfortunate reputation of being a "soft science" (Pigliucci 2002), in part as a consequence of lingering philosophical confusion about the nature of historical versus experimental research (Cleland 2002).

What the original Darwinism was really missing was not a solid philosophical foundation but rather a theory of heredity. Darwin famously struggled with it, alternatively flirting with both Lamarckism and his own theory of blending inheritance. Mendel published his seminal paper on the genetics of peas in 1865, soon after The Origin of Species and while Darwin was still active, but his work remained unknown until the turn of the century (the perils of publishing in obscure journals while pursuing an administrative career). In the meantime, however, Lamarckism was being securely expunged from evolutionary theory, mostly through the efforts of Wallace and those of August Weissman, who proposed the theory of separation of germ and somatic lines (which would soon prove to be inapplicable to many organisms, beginning with plants). It is this "Darwinism sans Lamarckism" that should be historically referred to as neo-Darwinism (not, as Ernst Mayr repeatedly pointed out, to be confused with the later MS).

By the turn of the century neo-Darwinism still did not have a theory of heredity, and the concept of natural selection itself was increasingly questioned in favor of alternatives such as orthogenesis and mutationism (Bowler 1983). Indeed, it was the latter notion, together with the emergence of the new discipline of "Mendelism," that caused a crisis in the field and seemed to spell the demise of Darwin's view 
of evolution. In a nutshell, it did not appear possible to reconcile Darwin's insistence on continuous variation and gradual evolution with the new data on discrete inheritance of Mendelian characters or with the equally discrete effect of mutations that began to be isolated in the laboratory. It was no coincidence that Thomas Hunt Morgan, one of the early Drosophila geneticists, initially accepted the idea of evolution but rejected the mechanism of natural selection.

The resolution of this impasse began with the classic work of Fisher (1918), Wright (1932), and Haldane (1932), who laid down the foundations of the field of population-statistical genetics. These authors elegantly showed that the joint expressions of several discrete Mendelian genes can cumulatively produce the effect of a continuous, Gaussian distribution of phenotypes. Not only was there no contradiction between Darwinism and Mendelism, but in fact the latter provided the much sought-after theory of heredity that had eluded Darwin and his contemporaries.

This interdisciplinary reconciliation, however, was only the beginning of the MS, which underwent a second, expansive phase during the 1930s and 1940s. The additional work took the shape of an impressive series of books by Dobzhansky (1937), Huxley (1942), Mayr (1942), Simpson (1944), and Stebbins (1950). The resulting body of theory truly deserves the appellation of "synthesis" in that it wove together not only neo-Darwinism and population genetics but also zoology, botany, paleontology, and natural history. Entire new fields of research, such as that focusing on speciation mechanisms, opened up, and old explanations, such as orthogenesis to account for macroevolutionary trends, were shown to be unnecessary as gradual Darwinism was extended to paleontological time scales.

The MS is still the accepted version of evolutionary theory, summarized in the following manner in one of the leading textbooks in the field (Futuyma 2006): "The major tenets of the evolutionary synthesis were that populations contain genetic variation that arises by random mutation and recombination; that populations evolve by changes in gene frequency brought about by random genetic drift, gene flow, and especially natural selection; that most adaptive genetic variants have individually slight phenotypic effects so that phenotypic changes are gradual; that diversification comes about by speciation, which normally entails the gradual evolution of reproductive isolation among populations; and that these processes, continued for sufficiently long, give rise to changes of such great magnitude as to warrant the designation of higher taxonomic levels."

\section{An Extended Synthesis}

The question that has been raised by an increasing number of evolutionary biologists over the past decade or so is whether, more than half a century after the consolidation of the MS, an update to the conceptual structure of evolutionary biology is needed (Rollo 1995; Schlichting \& Pigliucci 1998; Carroll 2000; Gould 2002; Muller 2007; Pigliucci 2007). The fundamental reason for an ES was put forth early on by philosopher Karl Popper (Platnick \& Rosen 1987) when he wrote that "[the MS] is strictly a theory of genes, yet the phenomenon that has to be explained in evolution is that of the transmutation of form." Actually, evolutionary theory needs to explain both the evolution of genes and the evolution of forms, and the MS, particularly through its population genetics backbone, does a good job at the former. The latter, however, has remained largely peripheral until the advent of "evo-devo" in the mid-1990s, and even so only the surface has arguably been scratched so far (Robert 2004).

More specifically, we can begin to articulate the need for an ES by posing a series of questions for which the MS provides partial answers or no answer at all. For instance: What causal roles does development play in evolution? Is evolutionary change always gradual (and what do we mean by "gradual")? Is natural 
selection the only organizing principle producing biological complexity? Does natural selection produce evolution at other hierarchical levels in addition to the organism, identified by Darwin, and the gene, added after the consolidation of the MS? Is there, once and for all, a discontinuity of some sort between so-called micro- and macroevolution (and again, can we agree on the meaning of these terms)? Is the question of inheritance completely settled or are there additional mechanisms besides the standard genetic one? How do novel phenotypes arise, and do they represent a distinct class of phenotypic change? How do ecology and evolutionary biology mesh; that is, can ecological and evolutionary theories be related?

A satisfactory exploration of these questions is obviously beyond the scope of this essay, but in the following I sketch the outline of some approaches that are being pursued (Table 1). This outline emerged largely from a workshop on the structure and future of evolutionary theory at the Konrad Lorenz Institute in Altenberg (Vienna, Austria) during the summer of 2008, the full proceedings of which will be published next year (Pigliucci \& Muller 2010). Of course, those present at Altenberg were but a sample of the theoretical biologists, empiricists, and philosophers of science that are actively involved in attempts to articulate an ES.

As a first issue, biological theory still must come to grips with the question of contingency versus necessity (Beatty 2006). Darwin himself highlighted the opportunism exhibited by natural selection in shaping biological forms, for instance, in the example of the flowers of an orchid species that are twisted $360^{\circ}$ to present a particular petal to the pollinator, because they derive from ancestors whose flower parts were already rotated by $180^{\circ}$. Jacques Monod (1971) and François Jacob (1977) famously wrote about the role of chance in evolution, and of course Gould (2002) made it a centerpiece of his evolutionary analyses. To some extent the issue is now becoming experimentally tractable (Travisano et al. 1995), but it is still marred by conceptually difficult issues con- cerning historicity (Cleland 2002) and whether it is possible, even in principle, to separate contingent from deterministic processes in evolution (Pigliucci \& Kaplan 2006).

Another issue is posed by the necessity for a significant renovation of the mathematical theory that accompanies the MS. One example concerns the models and especially the metaphor of the adaptive landscape that have guided population genetics theory virtually unquestioned throughout the 20th century. The idea was introduced by Wright (1932) to model the problem of the relative role of contingency versus necessity (where contingency is represented by the effects of genetic drift). Wright's metaphor generated a major line of mostly theoretical research hinging upon questions such as how populations effect a "peak shift" when they are stuck in a suboptimal area of the adaptive landscape. Modern computing power and a serious reanalysis of the whole idea of "landscape" suggests that, in the (ubiquitous) case of very high dimensionality, talk of "peaks," "valleys," and-a fortion - peak shifts, simply loses meaning (Gavrilets 2004; Pigliucci \& Kaplan 2006). It remains to be seen whether this is an instance of population genetics theory reaching its limits in terms of the degree of biological complexity it can handle (Dupré 1993) or if a new but substantial reformulation of its methods and conceptual domain will move things forward again.

A second example of expansion of the mathematical theory underpinning evolutionary biology is the idea of multilevel selection theory. This has been around for decades in the form of kin and group selection, but recently enough theoretical (and, to a much lesser extent, empirical) work has been done to put multilevel selection theory on the main stage of evolutionary research (Okasha 2006; Wilson \& Wilson 2007). It is now clear that several levels of the biological hierarchy are, at least theoretically, legitimate targets of selection, from genes to individuals, from groups of kin to populations to species (but, interestingly, and contrary to a relatively widespread opinion, not clades 
TABLE 1. Components of an Extended Synthesis, with Notes on their Stage of Conceptual Maturity; Degree of Empirical Support; Whether they Affect the Agency, Efficacy, or Scope of Natural Selection; and Some Key References ${ }^{a}$

\begin{tabular}{|c|c|c|c|c|}
\hline Component of ES & $\begin{array}{l}\text { Conceptual } \\
\text { maturity }\end{array}$ & $\begin{array}{l}\text { Empirical } \\
\text { support }\end{array}$ & $\begin{array}{l}\text { How it affects role } \\
\text { of natural selection }\end{array}$ & References \\
\hline $\begin{array}{l}\text { Expanded role of } \\
\text { contingency }\end{array}$ & High & Medium & $\begin{array}{l}\text { Decreases efficacy and } \\
\text { scope }\end{array}$ & $\begin{array}{l}\text { Monod 1971; Jacob 1977; } \\
\text { Travisano et al. 1995; } \\
\text { Cleland 2002; Gould } \\
\text { 2002; Beatty 2006; } \\
\text { Pigliucci \& Kaplan } \\
2006\end{array}$ \\
\hline $\begin{array}{l}\text { Revision of assumptions } \\
\text { and metaphors in } \\
\text { population genetics }\end{array}$ & Medium & Low & $\begin{array}{l}\text { Decreases efficacy and } \\
\text { scope }\end{array}$ & $\begin{array}{c}\text { Dupré 1993; Gavrilets } \\
\text { 2004; Pigliucci \& } \\
\text { Kaplan } 2006\end{array}$ \\
\hline Multilevel selection theory & High & Low & Increases agency & $\begin{array}{l}\text { Okasha 2006; Wilson \& } \\
\text { Wilson } 2007\end{array}$ \\
\hline $\begin{array}{l}\text { Studies of gene regulation, } \\
\text { gene network } \\
\text { properties, and the like } \\
\text { (related to genotype } \rightarrow \\
\text { phenotype map) }\end{array}$ & Medium & Medium & $\begin{array}{l}\text { Alters (i.e., may both } \\
\text { increase or decrease, } \\
\text { in different contexts) } \\
\text { efficacy and scope }\end{array}$ & $\begin{array}{l}\text { Cork \& Purugganan 2004; } \\
\text { Wray } 2007\end{array}$ \\
\hline $\begin{array}{l}\text { Evolvability, modularity, } \\
\text { and robustness (related } \\
\text { to genotype } \rightarrow \\
\text { phenotype map) }\end{array}$ & High & Medium & $\begin{array}{l}\text { Alters (i.e., may either } \\
\text { increase or decrease, } \\
\text { in different contexts) } \\
\text { efficacy and scope }\end{array}$ & $\begin{array}{l}\text { Wagner \& Altenberg } \\
\text { 1996; Wagner 2005; } \\
\text { Griswold 2006; } \\
\text { Colegrave \& Collins } \\
\text { 2008; Pigliucci 2008a }\end{array}$ \\
\hline Nongenetic inheritance & Medium & Low & Increases agency & $\begin{array}{l}\text { Oyama 1985; Griffiths \& } \\
\text { Gray 2004; Jablonka \& } \\
\text { Lamb 2005; Szathmáry } \\
\text { 2006; Chandler \& } \\
\text { Alleman } 2008\end{array}$ \\
\hline Nice construction & Medium & Low & Increases agency & $\begin{array}{l}\text { Odling-Smee } \text { et al. } 2003 \text {; } \\
\text { Laland \& Sterelny } \\
\text { 2006; Sultan } 2007\end{array}$ \\
\hline Biological emergence & Medium & Low to medium & $\begin{array}{c}\text { Decreases efficacy, } \\
\text { increases scope }\end{array}$ & $\begin{array}{l}\text { Kauffman 1993; Newman } \\
\text { et al. 2006; Kirschner \& } \\
\text { Gerhart } 2005\end{array}$ \\
\hline $\begin{array}{l}\text { Phenotypic plasticity in } \\
\text { macroevolution }\end{array}$ & Medium & Low & $\begin{array}{c}\text { Decreases efficacy, } \\
\text { increases scope }\end{array}$ & $\begin{array}{r}\text { West-Eberhard 2003; } \\
\text { Pigliucci et al. } 2006\end{array}$ \\
\hline $\begin{array}{l}\text { Stasis and other } \\
\text { macroevolutionary } \\
\text { patterns }\end{array}$ & Medium & High & $\begin{array}{l}\text { Probably decreases } \\
\text { efficacy and scope }\end{array}$ & $\begin{array}{l}\text { Eldredge \& Gould 1972; } \\
\text { Gould 2002; Jablonski } \\
\text { 2000, } 2008\end{array}$ \\
\hline
\end{tabular}

${ }^{a}$ Agency refers to the hierarchical levels at which natural selection acts, efficacy deals with the relative power of natural selection with respect to other potential causes of evolution, and scope is the degree to which natural selection can be extrapolated from micro- to macroevolutionary patterns and processes.

[Okasha 2006]). What emerges from these efforts is a much expanded role for natural selection itself, ironically somewhat of a return to Darwin's original thinking, breaking the theoretical straitjacket imposed by the MS for most of the 20th century.
A further area of extension of our view of evolution is to be found in research from a variety of fields that hinges directly or indirectly on the concept of a genotype $\rightarrow$ phenotype map. In some sense, this is a core issue for the ES because it directly addresses the 
need for a theory of form, as Popper put it, alongside the existing theory of gene changes. For instance, genomics and what I refer to as "postgenomics" (proteomics, metabolomics, etc.) started out squarely within the conceptual framework of the rather gene-centric MS, with the view that once we "decode" the genome of an organism we somehow gain a universal key to understanding its biology. The reality of organismal complexity has shattered such simplistic visions - the current emphasis in genomics research is no longer on the effects of individual genes or of single metabolic cascades but rather on the system-level properties of entire networks of gene products (Cork \& Purugganan 2004; Wray 2007), where what is still referred to as epistasis turns out to be in fact as universal a phenomenon, as Sewall Wright had predicted it would be.

The complexity of the genotype $\rightarrow$ phenotype map cannot be understood only by bottom-up approaches such as those that focus on gene networks and regulatory evolution, however. Accordingly, much discussion has been generated around a group of tightly related concepts such as modularity (the degree of interconnectedness of different traits), evolvability (the ability of living systems to further their own evolution), and robustness (the resilience of biological systems to perturbation) (Wagner \& Altenberg 1996; A. Wagner 2005; Griswold 2006; Colegrave \& Collins 2008; Pigliucci 2008a). There are several open questions here, including whether evolvability evolves solely as a by-product of neutral evolutionary mechanisms or under certain circumstances by natural selection. It also remains to be seen how to deploy the concepts of modularity and robustness across levels of complexity, from gene networks to morphological and even behavioral characters. Nonetheless, and contrary to recent skepticism (Lynch 2007), these ideas are here to stay.

As I mentioned earlier, a surprising question is being raised by recent research in both organismal and molecular biology: do we really know most of what there is to know about in- heritance? Arguments have been made that the very concept of "inheritance" has been much too narrowly construed within the MS and that causal factors in development beyond the genes, and perhaps extending even to aspects of the external environment, ought to be considered explicitly (Oyama 1985; Griffiths \& Gray 2004). Along similar, yet independent, lines it has been proposed that there are four, not just one, systems of inheritance affecting the evolution of biological organisms (Jablonka \& Lamb 2005): the standard genetic one, an epigenetic component (based on the inheritance of epigenetic markers, e.g., methylation patterns), a behavioral one (e.g., imitation in some species of animals), and a symbolic one (limited, as far as we know, to humans). This has prompted a rethinking of previously basic concepts in evolutionary theory, beginning with the idea of a "replicator" (Szathmáry 2006), as well as renewed efforts at empirical research exploring the extent and importance of heritable epigenetic effects (Chandler \& Alleman 2008).

A further aspect to the inheritance question explicitly links up ecology and evolutionary biology: the idea of niche construction (OdlingSmee et al. 2003; Laland \& Sterelny 2006). The basic concept amounts to rejecting the MS partition between organisms and environments, with the latter passive elements presenting "problems" that the former need to actively "solve" (through natural selection). Instead, niche construction presents a nuanced view of organism-environment interactions and coevolution, in which organisms constantly alter their environment, which in turn results in crucial elements of the environment being "inherited" both by the constructing species and by other members of the local ecosystem (the oft-cited example being dam construction by beavers).

I find the concept of niche construction compelling and important for an ES because it represents one of the few available examples of how ecology and evolutionary biology can be integrated. Such integration is a curiously largely unnoticed deficiency of the MS (as opposed to 
the widespread observation that the MS did not include developmental biology, for example). Although there is an entire field of "evolutionary ecology," which finds its roots in the empirical work of E.B. Ford (1964) and colleagues (and its theoretical underpinning in Fisherian statistical genetics), this barely scratches the surface of the field of ecology at large. Ecology has developed throughout the 20th century as an almost entirely independent field from evolutionary biology, a situation that surely needs to be rectified. One admittedly narrow bridge has recently begun under the term of "evo- $\mathrm{eco}^{-}$ devo" (Sultan 2007).

Continuing on this brief overview, we need to consider perhaps one of the most controversial new ideas that have been proposed: that emergent properties of biological systems provide an additional (not a substitute) mechanism to generate potentially adaptive complex phenotypes (Newman et al. 2006; Kirschner \& Gerhart 2005), which can then be screened by the standard process of natural selection. As is the case for other issues discussed in the preceding, this also is not a new idea but rather one that has been present at the margin of and sometimes downright in opposition tothe standard theory (Thompson 1917; Kauffman 1993). The basic concept corresponds again to a shift of perspective when compared with the stand taken by the MS: researchers interested in ideas such as "facilitated variation," "entrenchment," and the like are simply pointing out that living organisms are complex developing systems, not at all analogous to humanmade machines (despite the popularity of the latter metaphor). As such, living cells, tissues, and tissue systems are endowed with the ability to react systemically, and often adaptively, to changes in the environment-both in the classic sense of the external environment and in the sense of internal, genetic, and developmental environments.

The upshot of taking seriously the organicdevelopmental nature of living beings is that some fraction of biological complexity comes "for free," as it were, in the sense of being a natural outcome of the way living organisms develop. It is entirely unclear to me why several biologists allied to a strict interpretation of the MS are downright hostile to the very idea that natural selection might be facilitated by inherent properties of living organisms. It is as if the old internalist-externalist battle were still being fought (Resnik 1994), with the internalists implicitly (and sometimes explicitly) accused of subscribing to somewhat mystical notions of vitalism. Nothing could be further from the truth, and finally the empirical evidence in this area is beginning to accumulate to the point of undeniability (Newman et al. 2006; Kirschner \& Gerhart 2006).

Related to ideas about the emergent properties of developmental systems is the literature on the macroevolutionary role of phenotypic plasticity (West-Eberhard 2003; Pigliucci et al. 2006) via mechanisms such as genetic assimilation and phenotypic accommodation. In fact, the general property of accommodation by a developmental system of perturbations originating from either the external or the internal (genetic) environment is a necessary consequence of the inherent plasticity of living organisms. This represents a whole-organism analog of the ideas of facilitated variation and entrenchment mentioned above in terms of cell- and tissue-level properties. Here again evolution by natural selection gets something for free without violating any laws of physics (indeed, because of the existing laws of physics). One of the most surprising, and still hotly debated, consequences of seeing accommodation via plasticity playing a role in the origination of new phenotypes is that genes may be followers rather than leaders in evolution - at least some of the time. What is meant by this is that some phenotypic change may be initiated by the plastic accommodation of environmental disturbances, which may be accomplished by several organisms in a given population, simultaneously and on the basis of a heterogenous genetic background. If the resulting accommodated phenotype happens to be advantageous - and the frequency of this happening is of course a matter for empirical 
research to settle - then genetic combinations and/or mutations that stabilize the new phenotype will be selected in favor and will "canalize" the originally plastic response.

If mechanisms such as facilitation and accommodation are more frequent than previously imagined, then one of the consequences for evolutionary theory is that the gradual evolution described by MS-type population genetics models will not always account for macroevolutionary change on paleontological time scales. Accordingly, evidence is now accumulating that the predictive power of shortterm observations of evolutionary change (such as the classic examples of industrial melanism) is not strong at all when extrapolated over temporal scales that are orders of magnitude larger (Eldredge \& Gould 1972; Gould 2002). Evolutionary stasis, nonrandom origination of evolutionary novelties in time and space, and species selection are just some of the macroevolutionary phenomena that a view of evolution limited to the MS is simply ill equipped to deal with (Jablonski 2000, 2008).

\section{From Science to Philosophy and Back}

So far I have discussed some of what I think are the major scientific aspects of an ES. The ES, however, also presents philosophically interesting features, which, in turn, have consequences for the way scientists look at their own disciplines (Callebaut 2005; Love 2008; Pigliucci 2008b). To begin with, for instance, we should be under no misunderstanding that the proposed move from the MS to the ES represents a paradigm shift (Kuhn 1970) in evolutionary biology. Arguably, in fact, there has been no paradigm shift in this field since Darwin. A paradigm shift is understood in philosophy as a radical rethinking of the conceptual structure of a field of science, with the most often quoted examples all derived from the history of physics and astronomy: the rejection of the Ptolemaic system in favor of the Coper- nican one, or the replacement of Newtonian mechanics by Einstein's relativity. The last transition of that sort in biology was the rejection of Paley-style intelligent design (Paley 1802) (even though it survives still today in culture at large, as a particular form of creationism).

Instead, a good way to understand the import of the ES is to use Gould's (2002) scheme of the agency, efficacy, and scope of the explanatory principles put forth by an evolutionary theory, such as natural selection. Agency refers to the level(s) of the biological hierarchy at which a given causal principle acts; for natural selection within the context of the ES, agency is expanded by multilevel selection theory and nongenetic inheritance, for instance (Table 1). Efficacy deals with the relative power of a causal agent with respect to other potential agents; here the ES generally reduces the power of selection (e.g., because of expanded roles for phenomena such as emergence, plasticity, and macroevolutionary stasis not due to selection), which is one of the chief reasons of resistance by sustainers of the standard model (Table 1). As I was careful to note above, however, these mechanisms would still provide phenotypic variation that will need to be filtered by natural selection, but in an important sense they would contribute to diminishing - though by no means eliminating - the creative power of selection in evolution. Finally, we have scope, by which Gould meant the degree to which a causal process such as natural selection can be extrapolated from micro- to macroevolution. The ES envisioned here can either increase or decrease the scope of selection, depending on which other mechanisms one is considering: biological emergence and plasticity, for instance, will indirectly increase selection's scope, again because selection can act on the phenotypes thus generated, but contingency and stasis (which is not necessarily generated by natural selection, contra Estes \& Arnold 2007) will decrease selection's scope. All in all, then, the transition from the MS to the ES is generating some serious rethinking of the relative role of natural selection in evolution, although 


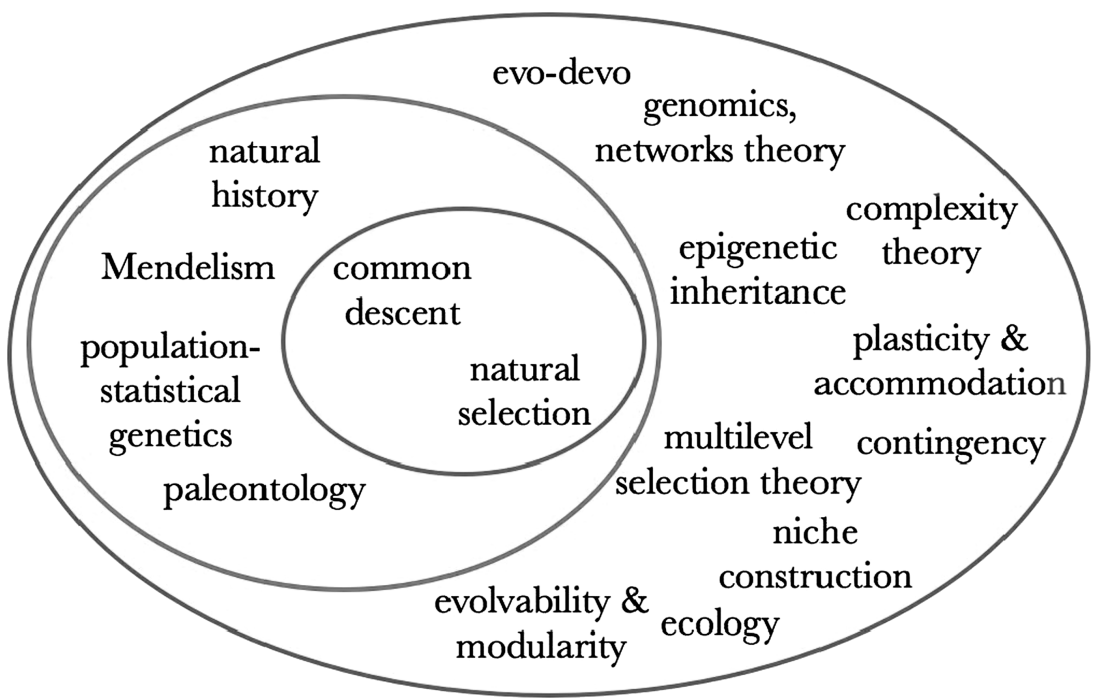

Figure 1. Conceptual representation of the continuous expansion of evolutionary theory in terms of ideas, phenomena studied, and fields of inquiry. The smallest ellipse represents the original Darwinism, the intermediate ellipse is the MS, and the largest ellipse stands for the ES.

this original Darwinian principle, like that of common descent, will remain a crucial component of our understanding of evolution (despite some exaggerated claims to the contrary [Reid 2007]).

Considering the combined perspectives of the history, current status, and possible future of evolutionary theory, we can summarize the shifts from the original "core" Darwinism to the MS (through the brief phases of neo-Darwinism and of the early synthesis) and then to the ES as a series of concentric, expanding ellipses (Fig. 1). The smallest ellipse represents the two cardinal concepts of Darwin's theory: common descent and natural selection. The second ellipse, the MS, added new ideas (Mendelism, the mathematical theory of population and statistical genetics) and unified fields of research (genetics, paleontology, natural history). Analogously, the third ellipse, the ES, continues the trend by incorporating more new ideas (e.g., complexity theory, epigenetic inheritance, and evolvability) and bringing under a unified umbrella further areas of inquiry (e.g., genomics, evo-devo, and potentially ecology). Because of the very nature of science, there is no pretense at all that the third ellipse will be the end of the story.

\section{Acknowledgments}

I thank Gerd Muller for his help in putting together the Altenberg symposium, which greatly expanded my own thinking about evolutionary theory. Thanks also to Oliver Bossdorf for very helpful comments on a previous draft of the manuscript.

\section{Conflicts of Interest}

The author declares no conflicts of interest.

\section{References}

Beatty, J. (2006). Replaying life's tape. F. Philos., 103, 336-362.

Bowler, P. J. (1983). The Eclipse of Darwinism. Baltimore, MD: Johns Hopkins University Press.

Callebaut, W. (2005). Again, what the philosophy of biology is not. Acta Biotheor., 53, 93-122.

Carroll, R. L. (2000). Towards a new evolutionary synthesis. Trends Ecol. Evol., 15, 27-32. 
Chandler, V., \& Alleman, M. (2008). Paramutation: epigenetic instructions passed across generations. Genetics, 178, 1839-1844.

Gleland, G. E. (2002). Methodological and epistemic differences between historical science and experimental science. Philos. Sci., 69, 474-496.

Colegrave, N., \& Collins, S. (2008). Experimental evolution and evolvability. Heredity, 100, 464470.

Cork, J. M., \& Purugganan, M. D. (2004). The evolution of molecular genetic pathways and networks. Bioessays, 26, 479-484.

Darwin, C. (1859/1910). The Origin of Species by Means of Natural Selection: Or, the Preservation of Favored Races in the Struggle for Life. New York: A.L. Burt.

Darwin, C., \& Wallace, A. R. (1858). Laws which affect the production of varieties, races, and species. Communication to the Linnean Society. http:// www.linnean.org/index.php?id=54.

Darwin, F., \& Seward, A. C. (Eds.) (1903). More Letters of Charles Darwin. A Record of his Work in a Series of Hitherto Unpublished Letters. London: John Murray.

Dobzhansky, T. (1937). Genetics and the Origin of Species. New York: Columbia University Press.

Dupré,J. (1993). The Disorder of Things: Metaphysical Foundations of the Disunity of Science. Cambridge, MA: Harvard University Press.

Eldredge, N., \& Gould, S. J. (1972). Punctuated equilibria: an alternative to phyletic gradualism. In T.J.M. Schopf. (Ed.), Models in Paleobiology (pp. 82-115). San Francisco: Freeman, Cooper and Co.

Estes, S., \& Arnold, S. J. (2007). Resolving the paradox of stasis: models with stabilizing selection explain evolutionary divergence on all timescales. Am. Nat., 169, 227-244.

Fisher, R. (1918). The correlation between relatives on the supposition of Mendelian inheritance. Trans. $R$. Soc. Edinb., 52, 399-433.

Ford, E. B. (1964). Ecological Genetics. London: Chapman and Hall.

Futuyma, D. (2006). Evolutionary Biology. Sunderland, MA: Sinauer.

Gavrilets, S. (2004). Fitness Landscapes and the Origin of Species. Princeton, NJ: Princeton University Press.

Gould, S. J. (2002). The Structure of Evolutionary Theory. Cambridge, MA: Harvard University Press.

Griffiths, P., \& Gray, R. D. (2004). The developmental systems perspective: organism-environment systems as units of development and evolution. In M. Pigliucci \& K. Preston. (Eds.), The Evolutionary Biology of Complex Phenotypes. Oxford, UK: Oxford University Press.

Griswold, C. K. (2006). Pleiotropic mutation, modularity and evolvability. Evol. Dev., 8, 81-93.

Haldane, J. B. S. (1932). The time of action of genes, and its bearing on some evolutionary problems. Am. Nat., $66,5-24$.

Huxley, J. S. (1942). Evolution: The Modern Synthesis. London: Allen \& Unwin.

Jablonka, E., \& Lamb, M.J. (2005). Evolution in Four Dimensions: Genetic, Epigenetic, Behavioral, and Symbolic Variation in the History of Life. Cambridge, MA: MIT Press.

Jablonski, D. (2000). Micro- and macroevolution: scale and hierarchy in evolutionary biology and paleobiology. Paleobiology, 26(S4), 15-52.

Jablonski, D. (2008). Species selection: theory and data. Annu. Rev. Ecol. Evol. Syst., 39, 501-524.

Jacob, F. (1977). Evolution and tinkering. Science, 196, 1161-1166.

Kauffman, S. A. (1993). The Origins of Order. New York: Oxford University Press.

Kirschner, M. W., \& Gerhart, J. C. (2005). The Plausibility of Life: Resolving Darwin's Dilemma. New Haven, CT: Yale University Press.

Kuhn, T. (1970). The Structure of Scientific Revolutions. Chicago: University of Chicago Press.

Laland, K. N., \& Sterelny, K. (2006). Seven reasons (not) to neglect niche construction. Evolution, 60, 17511762.

Love, A. C. (2008). From philosophy to science (to natural philosophy): evolutionary developmental perspectives. Q. Rev. Biol., 83, 65-76.

Lynch, M. (2007). The frailty of adaptive hypotheses for the origins of organismal complexity. Proc. Natl. Acad. Sci. USA, 104(suppl. 1), 8597-8604.

Mayr, E. (1942). Systematics and the Origin of Species. New York: Dover.

Mayr, E., \& Provine, W. B. (1980). The Evolutionary Synthesis. Perspectives on the Unification of Biology. Cambridge, MA: Harvard University Press.

Monod,J. (1971). Chance and Necessity; An Essay on the Natural Philosophy of Modern Biology. New York: Knopf.

Muller, G. B. (2007). Evo-devo: extending the evolutionary synthesis. Nat. Rev. Genet., 8, 943-949.

Newman, S. A., Forgacs, G., \& Muller, G. B. (2006). Before programs: the physical origination of multicellular forms. Int. F. Dev. Biol., 50, 289-299.

Odling-Smee, F. J., Laland, K. N., \& Feldman, M. W. (2003). Comments on Niche Construction: The Neglected Process in Evolution. Princeton, NJ: Princeton University Press.

Okasha, S. (2006). Evolution and the Levels of Selection. Oxford, UK: Oxford University Press.

Oyama, S. (1985). The Ontogeny of Information. Cambridge, UK: Cambridge University Press.

Paley, W. (1802). Natural Theology: Or, Evidences of the Existence and Attributes of the Deity, Collected from the Appearances of Nature. Boston: Gould, Kendall, and Lincoln.

Pigliucci, M. (2002). Are ecology and evolutionary biology "soft" sciences? Ann. Zool. Fenn., 39, 87-98. 
Pigliucci, M. (2007). Do we need an extended evolutionary synthesis? Evolution, 61, 27432749.

Pigliucci, M. (2008a). Is evolvability evolvable? Nat. Rev. Genet., 9, 75-82.

Pigliucci, M. (2008b). The borderlands between science and philosophy: an introduction. Q. Rev. Biol., 83, $7-15$.

Pigliucci, M., \& Kaplan, J. (2006). Making Sense of Evolution: The Conceptual Foundations of Evolutionary Biology. Chicago: Chicago University Press.

Pigliucci, M., \& Muller, G. (Eds.) (2010). Evolution: The Extended Synthesis. Cambridge, MA: MIT Press.

Pigliucci, M., Murren, C. J., \& Schlichting, C. D. (2006). Phenotypic plasticity and evolution by genetic assimilation. 7. Exp. Biol., 209, 2362-2367.

Platnick, N. I., \& Rosen, D. E. (1987). Popper and evolutionary novelties. Hist. Philos. Life Sci., 9, 5-16.

Reid, R. G. B. (2007). Biological Emergences: Evolution by Natural Experiment. Cambridge, MA: MIT Press.

Resnik, D. (1994). The rebirth of rational morphology: process structuralism's philosophy of biology. Acta Biotheor., 42, 1-14.

Robert, J. S. (2004). Embryology, Epigenesis, and Evolution: Taking Development Seriously. Cambridge, UK: Cambridge University Press.

Rollo, C. D. (1995). Phenotypes: Their Epigenetics, Ecology and Evolution. New York: Chapman \& Hall.

Schlichting, C. D., \& Pigliucci, M. (1998). Phenotypic Evolution, a Reaction Norm Perspective. Sunderland, MA: Sinauer.
Simpson, G. G. (1944). Tempo and Mode in Evolution. New York: Columbia University Press.

Stebbins, G. L. (1950). Variation and Evolution in Plants. New York: Columbia University Press.

Sultan, S. E. (2007). Development in context: the timely emergence of eco-devo. Trends Ecol. Evol., 22, 575582.

Szathmáry, E. (2006). The origin of replicators and reproducers. Philos. Trans. R. Soc. Lond. B Biol. Sci., 361: 1761-1776.

Thompson, D. (1917/1942). On Growth and Form. Cambridge, UK: Cambridge University Press.

Travisano, M., Mongold, J. A., Bennett, A. F., \& Lenski, R. E. (1995). Experimental tests of the roles of adaptation, chance, and history in evolution. Science, 267, 87-90.

Wagner, A. (2005). Robustness and Evolvability in Living Systems. Princeton, NJ: Princeton University Press.

Wagner, G. P., \& Altenberg, L. (1996). Complex adaptations and the evolution of evolvability. Evolution, 50, 967-976.

West-Eberhard, M. J. (2003). Developmental Plasticity and Evolution. Oxford, UK: Oxford University Press.

Wilson, D. S., \& Wilson, E. O. (2007). Rethinking the theoretical foundation of sociobiology. Q. Rev. Biol., $82,327-348$.

Wray, G. A. (2007). The evolutionary significance of cisregulatory mutations. Nat. Rev. Genet., 8, 206-216.

Wright, S. (1932). The roles of mutation, inbreeding, crossbreeding and selection in evolution. Proc. Sixth Int. Congr. Genet., 356-366. 